\title{
Polymorphism in propyl gallate recrystallized with acetone
}

\author{
D. A. Gálico ${ }^{1,2} \cdot$ C. V. Nova ${ }^{1,3} \cdot$ G. Bannach ${ }^{1}$
}

Received: 11 August 2016/ Accepted: 20 October 2016/Published online: 27 October 2016

(C) Akadémiai Kiadó, Budapest, Hungary 2016

\begin{abstract}
A new polymorphic form of the synthetic antioxidant propyl gallate was obtained by the recrystallization of the compound in acetone. The new form was characterized by thermogravimetry, differential scanning calorimetry, X-ray powder diffractometry, and near- and middle-infrared region spectroscopy. While the commercial form of propyl gallate starts to melt at $145^{\circ} \mathrm{C}$ with the maximum temperature of the peak at $150{ }^{\circ} \mathrm{C}$, the recrystallized form starts to melt at $140{ }^{\circ} \mathrm{C}$ with the maximum temperature of the peak at $148.8^{\circ} \mathrm{C}$. The two forms differ much in the X-ray powder diffractograms pattern, confirming the change in the longdistance interactions in both forms but the near- and middleinfrared region spectroscopy shows that no difference occurs in the inter- and intramolecular interactions.
\end{abstract}

Keywords Propyl gallate - Thermal behavior .

Polymorphism $\cdot$ Food additive

\section{Introduction}

Propyl gallate, or $n$-propyl 3,4,5-trihydroxybenzoate (PG), is a synthetic antioxidant used as a food additive $(E=310)$; it is mainly added to foods containing oils and fats to prevent oxidation. Its molecular form is $\mathrm{C}_{10} \mathrm{H}_{12} \mathrm{O}_{5}$, and it has a molecular weight of $212.20 \mathrm{~g} \mathrm{~mol}^{-1}$; its

D. A. Gálico

dagbau@hotmail.com

1 Departamento de Química, Faculdade de Ciências, UNESP Univ Estadual Paulista, Bauru, SP CEP 17033-260, Brazil

2 Instituto de Química, UNICAMP - Univ Estadual de Campinas, Campinas, SP CEP 13083-970, Brazil

3 UNIP - Univ Paulista, Bauru, SP CEP 17048-290, Brazil structure is shown in Fig. 1 [1, 2]. PG also finds applications in the cosmetics, pharmaceuticals, food packing, and lubricants fields [3, 4].

Recently, our group has studied the thermal behavior and spectroscopic properties of the PG antioxidant [5]; PG is thermally stable up to $200{ }^{\circ} \mathrm{C}$, starts to melt at $145^{\circ} \mathrm{C}$, and after melted, recrystallizes in a different crystalline form. This ability of a crystalline solid to exist in different crystalline forms is called polymorphism and can lead to changes in physical-chemical properties of the compound, e.g., the solubility and bioavailability; consequently, the same compound may exhibit different toxicity level depending on the crystalline form $[6,7]$.

Polymorphism is a very important property in the pharmaceutical and food sciences [8-10], and the study of the possible polymorphic forms helps in the understanding and proposal of the best storage conditions, interactions, and compatibilities of the interest compound.

Thermal methods of analysis have been widely used in the pharmaceutical and food areas to detect the thermal stability [11], evaluation of the thermal decomposition kinetics [12], and gaseous products of the thermal decomposition [13], solid-state reactions [14], and as one of the main methods in the detection of polymorphic forms [6].

Thus, this research aims to the obtainment and characterization of a new polymorphic form of PG obtained by the recrystallization of the compound in acetone.

\section{Experimental}

\section{Thermal studies}

Propyl gallate with $\geq 98 \%$ purity was purchased from Aldrich. Simultaneous TG-DTA curves were obtained 
<smiles>CCCOC(=O)c1cc(O)c(O)c(O)c1</smiles>

Fig. 1 Structure of propyl gallate

using STA 449 F3 Jupiter (Netzsch) thermal analysis equipment, under the following experimental conditions: open $\alpha$-alumina crucibles, heating rate of $20^{\circ} \mathrm{C} \mathrm{min}^{-1}$, air atmosphere at a $50 \mathrm{~mL} \mathrm{m^{-1 }}$ flow, and samples of about $15 \mathrm{mg}$.

The DSC curve was obtained using a DSC 1 systems (Mettler Toledo) under the following experimental conditions: aluminum crucible with perforated cover, heating rate of $10{ }^{\circ} \mathrm{C} \mathrm{min}{ }^{-1}$, air atmosphere at $100 \mathrm{~mL} \mathrm{~min}^{-1}$ flow, and sample of about $3 \mathrm{mg}$.

The X-ray powder diffractograms were obtained on a Rigaku DMAX Ultima + X-ray diffractometer using $\mathrm{Cu}$ $K \alpha$ radiation $(\lambda=1.541 \AA)$ and settings of $40 \mathrm{kV}$ and $20 \mathrm{~mA}$.

\section{Spectroscopic studies}

Middle-infrared spectra (MIR) were collected on a Bomem FTIR MB100 spectrophotometer within the $4000-400 \mathrm{~cm}^{-1}$ range, with $\mathrm{KBr}$ pellets, in transmittance mode.

Near infrared spectra (NIR) were collected on a Thermo Scientific Antaris II spectrophotometer by reflectance within the $10,000-4000 \mathrm{~cm}^{-1} \mathrm{~nm}$ range.

\section{Crystallization}

In $15 \mathrm{~mL}$ of acetone, $250 \mathrm{mg}$ of PG was solubilized. The solution was kept in a refrigerator at a temperature of $4{ }^{\circ} \mathrm{C}$. After 10 days, the solution started to precipitate, and the crystals were separated of the supernatant and dried in a low-pressure desiccator with $\mathrm{CaCl}_{2}$.

\section{Results and discussion}

\section{Thermal studies}

The TG-DTA curves are shown in Fig. 2. Both curves, for the commercial sample (Fig. 2a) and for the recrystallized sample (Fig. 2b), present the same profile, presenting

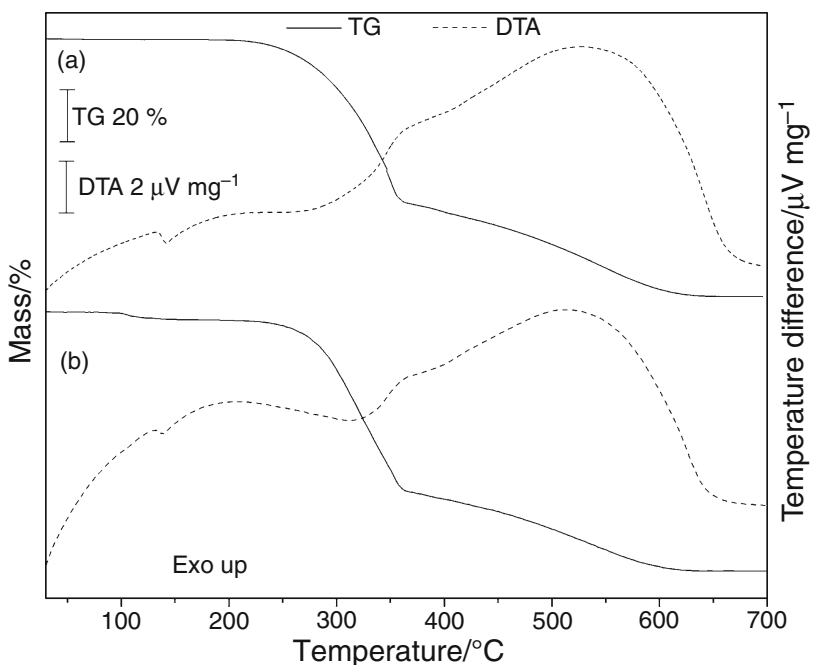

Fig. 2 TG-DTA curves of a commercial sample of PG $(m=15.05 \mathrm{mg})$ and $\mathbf{b}$ recrystallized form of PG $(m=14.98 \mathrm{mg})$

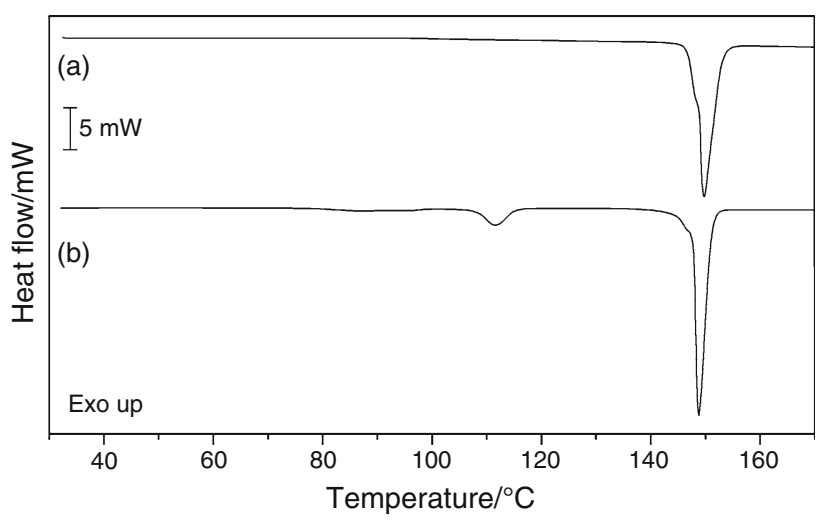

Fig. 3 DSC curves of a commercial sample of PG $(m=3.30 \mathrm{mg})$ and $\mathbf{b}$ recrystallized form of PG $(m=3.31 \mathrm{mg})$

thermal stability until approximately $200{ }^{\circ} \mathrm{C}$ and thermal decomposition in two main steps; these observations are in agreement with our previous work [5] and demonstrated that both forms have the same thermal behavior. For the recrystallized sample, a mass loss in the $85-130^{\circ} \mathrm{C}$ range $(2.90 \%)$ occurs due to the loss of solvent molecules.

The DSC curves are shown in Fig. 3. As mentioned in our previous work, the melting of commercial PG (Fig. 3a) starts at $145{ }^{\circ} \mathrm{C}$ (endothermic event), with a maximum peak temperature at $150{ }^{\circ} \mathrm{C}$ and melting heat of $23.72 \mathrm{~kJ} \mathrm{~mol}^{-1}$. In the case of the recrystallized form of PG (Fig. 3b), the melting starts at $140{ }^{\circ} \mathrm{C}$, with a maximum peak at $148.8{ }^{\circ} \mathrm{C}$ and melting heat of $23.13 \mathrm{~kJ} \mathrm{~mol}^{-1}$. This $1.2{ }^{\circ} \mathrm{C}$ difference in the melting peak of the samples strongly suggests the presence of two distinct polymorphic forms; furthermore, in the DSC curve of the recrystallized sample, it is noted the presence of another endothermic event starting at $105{ }^{\circ} \mathrm{C}$, with a maximum peak at $111{ }^{\circ} \mathrm{C}$ 


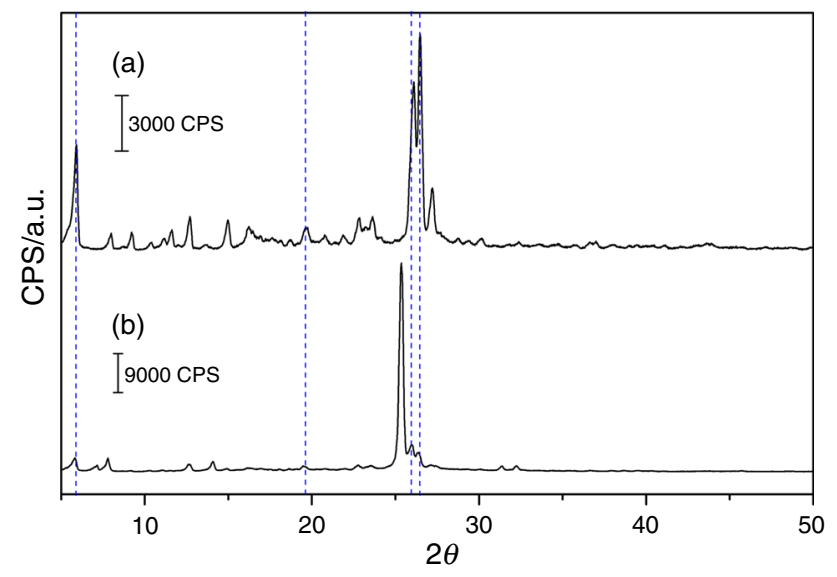

Fig. 4 X-ray powder diffractograms of a commercial sample of PG and $\mathbf{b}$ recrystallized form of PG

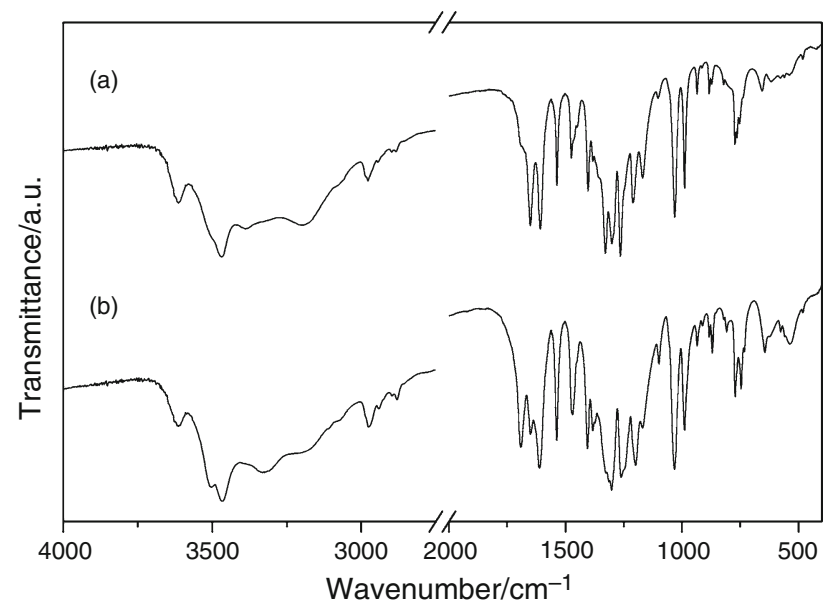

Fig. 5 MIR spectra of a commercial sample of PG and $\mathbf{b}$ recrystallized form of PG

due to the desolvation of the compound and a desolvation heat of $3.95 \mathrm{~kJ} \mathrm{~mol}^{-1}$.

The X-ray powder diffractograms were used to confirm the polymorphism and are shown in Fig. 4. The great difference between the two diffractograms confirms the presence of two distinct crystalline forms for the commercial (Fig. 4a) and recrystallized (Fig. 4b) samples.

MIR and NIR spectra were used to confirm that the two samples really correspond to PG compound and exclude the possibility of some degradation during recrystallization; MIR and NIR spectra are shown in Figs. 5 and 6, respectively. No significant difference is noted in both spectra, confirming that no degradation occurs, and no difference in inter- and intramolecular interactions exists in both polymorphic forms. Some small difference in the spectra of the recrystallized sample (e.g., the intense band at $1694 \mathrm{~cm}^{-1}$ ) is due to the interaction of the acetone with the compound. For the complete assignment of the bands, the reader can read our previous work [5].

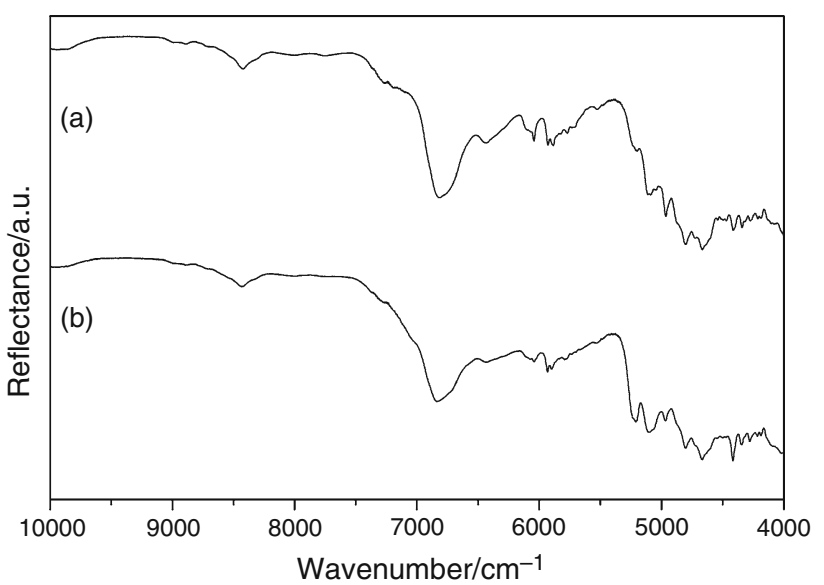

Fig. 6 NIR spectra of a commercial sample of PG and b recrystallized form of PG

Thus, with these data, it is possible to confirm the presence of a new polymorphic form of the PG when recrystallized with acetone. It is not the focus of this work to discuss the possible differences in bioavailability and/or toxicity of this new form. The main purpose of this paper is to highlight the necessity of the evaluation of possible polymorphic forms in food additives since there is a lack of studies in this area, unlike what occurs in the pharmaceutical field and demonstrates the importance of thermal methods of analysis in the screening of new polymorphic forms.

\section{Conclusions}

A new polymorphic form of the synthetic antioxidant propyl gallate was obtained when the compound has recrystallized in an acetone solution. The thermogravimetric data show that no difference in the thermal behavior occurs in both forms, but the recrystallized form has a first mass loss due to the desolvation. DSC curves show the difference in the melting range of the two forms; while the commercial form of PG starts to melt at $145{ }^{\circ} \mathrm{C}$, with the maximum of the peak at $150{ }^{\circ} \mathrm{C}$, the recrystallized form starts to melt at $140{ }^{\circ} \mathrm{C}$, with a maximum at $148.8^{\circ} \mathrm{C}$. The great difference between the $\mathrm{X}$-ray powder diffractograms confirms that the recrystallization leads to a different crystal form of PG, confirming the distinct polymorphic forms. MIR and NIR spectra shown that no difference in the inter- and intramolecular interactions occurs in these two forms. With this work, we can conclude the necessity and importance of the evaluation of possible polymorphic forms in food additives and related compounds to the quality control in this area. 
Acknowledgements The authors would like to thank the FAPESP (Procs. 2012/21450-1 and 2013/09022-7) and CNPq foundations (Brazil) for their financial support.

\section{References}

1. EFSA Panel on Food additives and Nutrient Sources added to Food (ANS). Scientific opinion on the re-evaluation of propyl gallate (E 310) as a food additive. EFSA J. 2014;12:3642-88.

2. Bal MO, Tuner H. H dosimetry and radical kinetics of gammairradiated propyl gallate. J Mol Struct. 2014;1071:123-7.

3. Wang JY, Wu HL, Chen Y, Zhai M, Qing XD, Yu RQ. Quantitative determination of butylated hydroxyanisole and n-propyl gallate in cosmetics using three-dimensional fluorescence coupled with second-order calibration. Talanta. 2013;116:347-53.

4. Han YH, Moon HJ, You BR, Kim SZ, Kim SH, Park WH. Propyl gallate inhibits the growth of HeLa cells via caspase dependent apoptosis as well as a G1 phase arrest of the cell cycle. Oncol Rep. 2010;23:1153-8.

5. Gálico DA, Nova CV, Guerra RB, Bannach G. Thermal and spectroscopic studies of the antioxidant food additive propyl gallate. Food Chem. 2015;182:89-94.

6. Giron D. Investigations of polymorphism and pseudo-polymorphism in pharmaceuticals by combined thermoanalytical techniques. J Therm Anal Calorim. 2001;64:37-80.

7. Giron D. Monitoring of polymorphism-from detection to quantification. Eng Life Sci. 2003;3:103-12.
8. Shamai K, Bianco-Peled H, Shimoni E. Polymorphism of resistant starch type III. Carbohydr Polym. 2003;54:363-9.

9. Ali A, Selamat J, Che Man YB, Suria AM. Effect of storage temperature on texture, polymorphic structure, bloom formation and sensory attributes of filled dark chocolate. Food Chem. 2001;72:491-7.

10. O'Sullivan B, Glennon B. Application of in situ FBRM and ATRFTIR to the monitoring of the polymorphic transformation of D-mannitol. Org Process Res Dev. 2005;9:884-9.

11. Guerra RB, Gálico DA, Holanda BBC, Bannach G. Solid-state thermal and spectroscopic studies of the anti-inflammatory drug sulindac using UV-Vis, MIR, NIR, DSC, simultaneous TG-DSC, and the coupled techniques TG-EGA-MIR and DSC-optical microscopy. J Therm Anal Calorim. 2016;123:2523-30.

12. Pătruţescu C, Vlase G, Turcuş V, Ardelean D, Vlase T, Albu P. TG/DTG/DTA data used for determining the kinetic parameters of the thermal degradation process of an immunosuppressive agent: mycophenolate mofetil. J Therm Anal Calorim. 2015;121:983-8.

13. Silva ACM, Gálico DA, Guerra R, Perpétuo GL, Legendre AO, Rinaldo D, Bannach G. Thermal stability and thermal decomposition of the antihypertensive drug amlodipine besylate. J Therm Anal Calorim. 2015;120:889-92.

14. Gálico DA, Holanda BBC, Perpétuo GL, Schnitzler E, Treu-Filho O, Bannach G. Thermal and spectroscopic studies on solid Ketoprofen of lighter trivalent lanthanides. J Therm Anal Calorim. 2012;108:371-9. 